\title{
Implementation of a microsurgical breast reconstruction program in Mexico
}

Breast cancer is the most common malignancy in Latin America and in Mexico (Chávarri-Guerra et al., 2012; Reynoso-Noveron et al., 2017), and providing multidisciplinary care for patients with breast cancer represents a major challenge for healthcare systems throughout the region (Chávarri-Guerra et al., 2012; Reynoso-Noveron et al., 2017). Since 2007, the Mexican government, through the Seguro Popular insurance system, has provided coverage for breast cancer treatment (Chávarri-Guerra et al., 2012;Consejo de Salubridad General, 2011; Reynoso-Noveron et al., 2017). Unfortunately, Seguro Popular does not cover other interventions, such as reconstructive surgery (Consejo de Salubridad General, 2011; Reynoso-Noveron et al., 2017). The National Cancer Institute of Mexico (INCan) provides care under Seguro Popular coverage, and although breast reconstruction was available, its cost had to be covered out-of-pocket until 2012, when a federal government grant helped establish the Post-Mastectomy Program (PMP), aimed at providing free reconstruction (Cuenta De La Hacienda Pública Federal, 2013). Here, we describe the implementation of a breast reconstructive microsurgery program at INCan, with the intent of fostering the development of similar programs in other low-and-middle-income countries (LMIC).

Before PMP, most patients were treated with tissue expanders and implants, while others received reconstruction using myocutaneous flaps, with approximately 40 reconstructions performed yearly. With the establishment of PMP, we have progressively built the capacity to perform microsurgical reconstruction with deep inferior epigastric perforator (DIEP) flaps in addition to implant-based reconstruction. Objectives of the microsurgical reconstruction program are summarized in Figure 1.

All newly diagnosed patients with breast cancer, as well as those with nonmalignant diseases who are candidates for reconstruction, are discussed by a multidisciplinary team including plastic surgeons. Patients desiring reconstruction are evaluated by anesthesiologists and undergo an abdominal tomography to visualize the deep inferior epigastric artery. DIEP flap candidates are evaluated by a plastic surgeon who explains the procedure and its complications, including planned number of inpatient days, length, expected cosmetic results, postoperative care, and potential need for further interventions. Patients complete the Spanish version of the BREAST-QTM (Memorial Sloan-Kettering Cancer Center and The University of British Columbia()) quality of life questionnaire. Microsurgical procedures are performed by a plastic surgeon with microsurgery training and a microsurgery fellow using a Carl Zeiss Pentero ${ }^{\circledR}$ microscope. Data on ischemia time, time for surgical anastomosis, and vessel anatomy is recorded for each procedure.

In 2012, only 6 microsurgical reconstructions were performed at INCan. From January 2013 to December 2017, 161 microsurgical reconstructions have been performed, going from 23 in 2013 to 34 in 2017. In 160 cases DIEP flaps were performed, while in 1 case another technique was utilized (gluteal artery perforator flap). Patient and surgical characteristics are outlined in Table 1.

Capacity-building is fundamental to our program. Twenty-three surgeons from Spanish-speaking nations have been trained in reconstructive breast microsurgery (Figure 2): 10 from Mexico; 5 from Colombia; 5 from Argentina; and 3 from Spain. Two fellows from countries outside the Ibero-American region (United States and Italy) have also been trained. In 2019, the first Central American fellow (Costa Rica) will complete training. Additionally, we offer a 2-week course targeted toward plastic surgeons wanting to obtain or enhance their microsurgical skills.

In Latin America, most patients with breast cancer present with advanced disease, and up to $80 \%$ of women are treated with

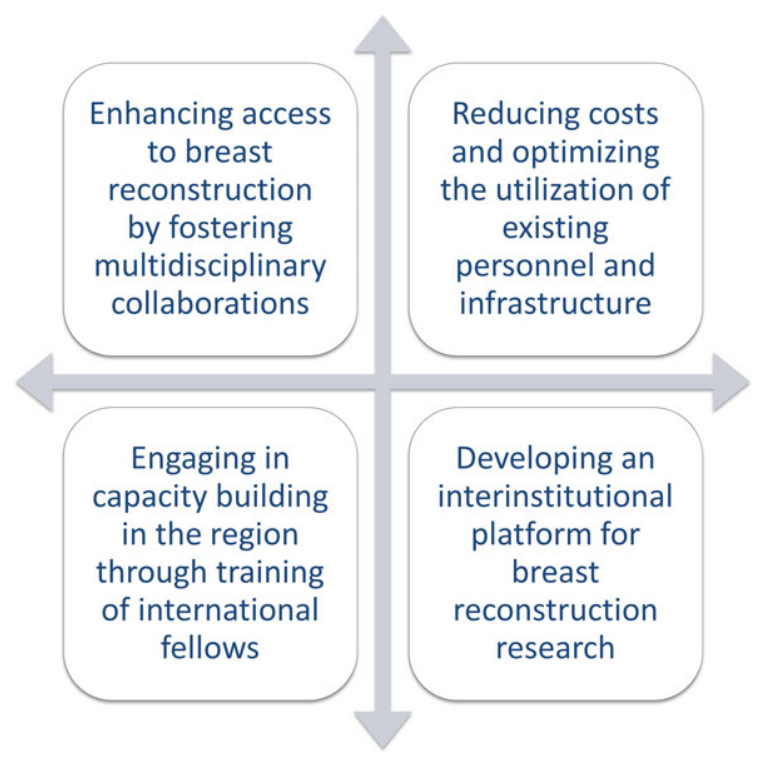

FIGURE 1 Objectives of the microsurgical breast reconstruction program at INCan 
TABLE 1 Characteristics of patients undergoing microsurgical breast reconstruction at INCan between 2013 and 2017

\begin{tabular}{|c|c|c|}
\hline Characteristics & $N(161)$ & $\%$ \\
\hline Median age, years (range) & $45(21-66)$ & \\
\hline Body mass index, median (range) & $26.8(18.2-39)$ & \\
\hline \multicolumn{3}{|l|}{ Educational level } \\
\hline None & 3 & 1.9 \\
\hline Elementary school & 26 & 16.1 \\
\hline Middle school & 63 & 39.1 \\
\hline High school/technical & 37 & 23.0 \\
\hline College & 32 & 19.9 \\
\hline \multicolumn{3}{|l|}{ Year of reconstruction } \\
\hline 2013 & 23 & 14.3 \\
\hline 2014 & 31 & 19.3 \\
\hline 2015 & 32 & 19.9 \\
\hline 2016 & 41 & 25.5 \\
\hline 2017 & 34 & 21.0 \\
\hline \multicolumn{3}{|l|}{ Smoking status } \\
\hline Never smoker & 133 & 82.6 \\
\hline Former smoker & 15 & 9.3 \\
\hline Current smoker & 13 & 8.1 \\
\hline Diabetes & 4 & 2.5 \\
\hline Hypertension & 16 & 9.9 \\
\hline Rheumatic diseases & 4 & 2.5 \\
\hline \multicolumn{3}{|c|}{ American Society of Anesthesiologists risk category } \\
\hline 0 & 1 & 0.6 \\
\hline 1 & 110 & 68.3 \\
\hline 2 & 50 & 31.1 \\
\hline Previous abdominal scars & 105 & 66.5 \\
\hline \multicolumn{3}{|l|}{ Reason for reconstruction } \\
\hline Invasive breast cancer & 111 & 68.9 \\
\hline Ductal carcinoma in situ & 19 & 11.8 \\
\hline BRCA mutation & 9 & 5.6 \\
\hline Phyllodes tumor & 8 & 5.0 \\
\hline Patient preference & 8 & 5.0 \\
\hline Breast sarcoma & 4 & 2.5 \\
\hline Xanthogranulomatous mastitis & 2 & 1.2 \\
\hline \multicolumn{3}{|l|}{ Invasive breast cancer stage $(N=109)$} \\
\hline IA & 23 & 20.9 \\
\hline IB & 1 & 0.9 \\
\hline IIA & 38 & 34.5 \\
\hline IIB & 25 & 22.7 \\
\hline IIIA & 13 & 11.8 \\
\hline IIIB & 6 & 5.5 \\
\hline IIIC & 3 & 2.7 \\
\hline Received neoadjuvant chemotherapy & 34 & 21.7 \\
\hline Received adjuvant chemotherapy & 51 & 31.7 \\
\hline Received adjuvant radiotherapy & 47 & 29.2 \\
\hline \multicolumn{3}{|l|}{ Timing of reconstruction } \\
\hline Immediate unilateral DIEP & 89 & 55.1 \\
\hline Immediate bilateral DIEP & 35 & 21.5 \\
\hline Late DIEP reconstruction & 36 & 22.4 \\
\hline Median days in hospital (range) & $6(2-17)$ & \\
\hline $\begin{array}{l}\text { Perioperative complications requiring } \\
\text { reoperation }\end{array}$ & 42 & 26.1 \\
\hline Partial/total flap loss & 21 & 13.0 \\
\hline
\end{tabular}

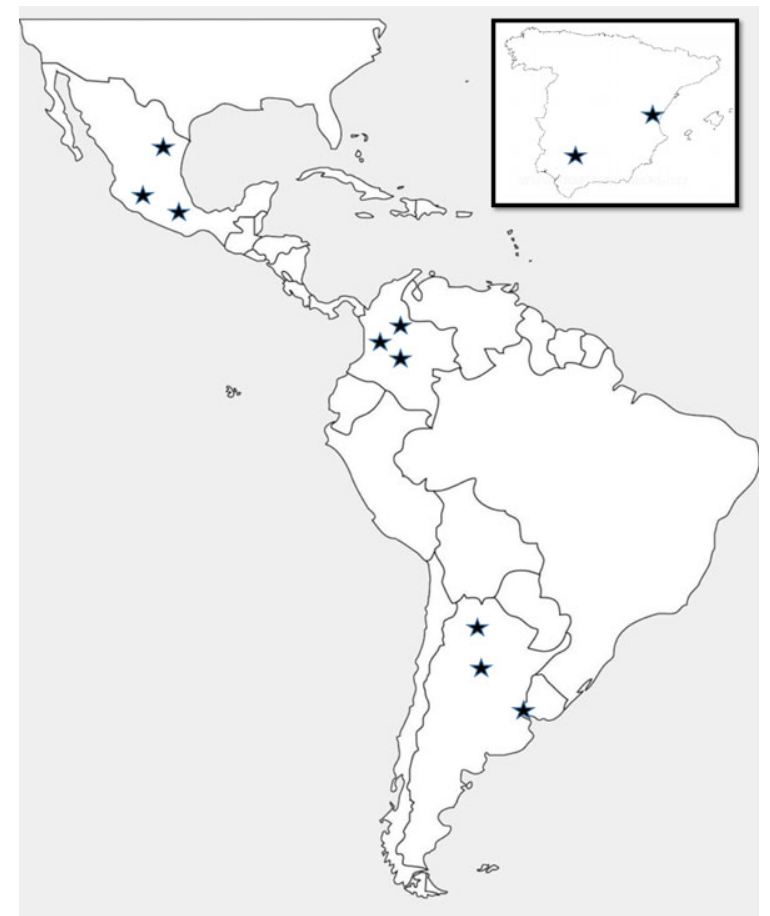

FIGURE 2 Geographical origin of microsurgical fellows trained at INCan across Ibero-American countries

mastectomy (Chávarri-Guerra et al., 2012; Di Sibio, Abriata, Forman, \& Sierra, 2016). This means that most breast cancer survivors in the region are candidates for reconstruction, which unfortunately is not covered by most healthcare systems. Although in settings with basic resources, surgical care should focus on providing curative-intent surgery, upper-middle income countries should strive to provide breast reconstruction in order to improve quality of care (Anderson et al., 2008).

Little is known about the status of both breast reconstruction and microsurgery in Latin America. A survey conducted among plastic surgeons in Argentina showed that most respondents performed less than 25 breast reconstructions per year, of which $80 \%$ were implantbased (Mayer, de Belaustegui, \& Loustau, 2018). Another study from Brazil reported that only 3,161 of the 10,831 women undergoing mastectomy in 2014 received reconstruction, despite the availability of coverage within the public healthcare system (Freitas-Júnior et al., 2017).

As part of our future plans, we intend to influence policy makers into including reconstructive surgery into the care of patients with breast cancer in Seguro Popular, to analyze the complication rates and outcomes of patients living in resource-limited settings after reconstruction, and to test the cost-effectiveness of our microsurgical program compared with implant-based reconstructions. Additionally, we are building a network of former fellows as a starting point for future collaborations to study microsurgical breast reconstruction in LMIC.

Our experience implementing a microsurgical breast reconstruction program at a public cancer center in a LMIC showcases a self-sustainable, publicly funded multidisciplinary project, and we believe it can serve as a blueprint for other institutions. Programs like ours, in 
which physicians from LMIC learn from each other, are fundamental for global surgery.

\section{ACKNOWLEDGMENT}

This work was supported by the P017 Reproductive Health and Gender Equality in Health Grant from the Mexican Federal Government.

\section{ORCID}

Enrique Soto-Perez-de-Celis (D) https://orcid.org/0000-00027301-2163

Johnatan Figueroa-Padilla MD ${ }^{1}$
Enrique Soto-Perez-de-Celis MD, MSc ${ }^{1,2}$
Alejandro Maciel-Miranda MD
Daniela Vargas-Salas MD ${ }^{1}$
Eric Santamaria MD ${ }^{1}$
Nereida Esparza-Arias MD ${ }^{1}$
Luz M. Gutiérrez-Zacarías MD ${ }^{1}$
Paula Cabrera-Galeana MD ${ }^{1}$
Enrique Bargalló-Rocha MD ${ }^{1}$
${ }^{1}$ Post-Mastectomy Program, Department of Breast Tumors, Instituto
Nacional de Cancerología, Mexico City, Mexico
${ }^{2}$ Department of Geriatrics, Instituto Nacional de Ciencias Medicas y
Nutrición Salvador Zubiran, Mexico City, Mexico
Correspondence
de Cancerología, Avenida San Fernando 22, Belisario Domínguez Secc

16, 14080 Tlalpan, Mexico City, Mexico. Email: ebargallo@yahoo.com

\section{REFERENCES}

Anderson, B. O., Yip, C. H., Smith, R. A., Shyyan, R., Sener, S. F., Eniu, A., ... Harford, J. (2008). Guideline implementation for breast healthcare in low-income and middle-income countries: Overview of the breast health global initiative global summit 2007. Cancer, 113, 2221-2243.

Chávarri-Guerra, Y., Villarreal-Garza, C., Liedke, P. E., Knaul, F., Mohar, A., Finkelstein, D. M., \& Goss, P. E. (2012). Breast cancer in Mexico: A growing challenge to health and the health system. The Lancet Oncology, 13, e335-e343.

Consejo de Salubridad General. Identificación de Tratamientos y Medicamentos Asociados a Gastos Catastróficos. PROTOCOLO TÉCNICO. Enfermedad CIE.10: C50 Tumor maligno de la mama, Mexico, 2011.

Cuenta De La Hacienda Pública Federal. Análisis Del Ejercicio Del Presupuesto De Egresos Instituto Nacional De Cancerología. Retrieved from http://www.apartados.hacienda.gob.mx/contabilidad/documentos/ informe_cuenta/2013/doc/t7/NBV/NBV.02.02.07.vd.pdf, 2013.

Di Sibio, A., Abriata, G., Forman, D., \& Sierra, M. S. (2016). Female breast cancer in Central and South America. Cancer Epidemiology, 44, S110-S120.

Freitas-Júnior, R., Gagliato, D. M., Moura Filho, J. W. C., Gouveia, P. A., Rahal, R. M. S., Paulinelli, R. R., ... Lucena, C. M. (2017). Trends in breast cancer surgery at Brazil's public health system. Journal of Surgical Oncology, 115, 544-549.

Mayer, H. F., de Belaustegui, E. A., \& Loustau, H. D. (2018). Current status and trends of breast reconstruction in Argentina. Journal of Plastic, Reconstructive \& Aesthetic Surgery, 71, 607-609.

Reynoso-Noveron, N., Villarreal-Garza, C., Soto-Perez-de-Celis, E., Arce-Salinas, C., Matus-Santos, J., Ramirez-Ugalde, M. T., ... Mohar, A. (2017). Clinical and epidemiological profile of breast cancer in Mexico: Results of the Seguro popular. Journal of Global Oncology, 3, 757-764. 